\title{
The Impact of Malaria Control Interventions on Malaria and Anaemia in Children under Five after Ten Years of Implementation in the Hohoe Municipality of Ghana
}

\author{
Margaret Kweku', Eric Kwaku Appiah'2 ${ }^{2}$ Yeetey Enuameh ${ }^{3}$, Martin Adjuik', Wisdom Takramah', \\ Elvis Tarkang ${ }^{1}$, John Gyapong ${ }^{4}$
}

\begin{abstract}
${ }^{1}$ School of Public Health, University of Health and Allied Sciences, Ho, Ghana
${ }^{2}$ Dept. of Epidemiology, Surveillance and Disease Control, Public Health Division, 37 Military Hospital, Accra, Ghana

${ }^{3}$ Dept. of Epidemiology and Biostatistics, School of Public Health, Kwame Nkrumah University of Science and Technology,

Kumasi, Ghana

${ }^{4}$ Office of the Vice Chancellor, University of Health and Allied Sciences, Ho, Ghana

Email:mkweku@uhas.edu.gh, margaretkweku069@gmail.com
\end{abstract}

How to cite this paper: Kweku, M., Appiah, E.K., Enuameh, Y., Adjuik, M., Takramah, W., Tarkang, E. and Gyapong, J. (2017) The Impact of Malaria Control Interventions on Malaria and Anaemia in Children under Five after Ten Years of Implementation in the Hohoe Municipality of Ghana. Advances in Infectious Diseases, 7, 93-105.

https://doi.org/10.4236/aid.2017.73010

Received: February 28, 2017

Accepted: September 17, 2017

Published: September 20, 2017

Copyright @ 2017 by authors and Scientific Research Publishing Inc. This work is licensed under the Creative Commons Attribution International License (CC BY 4.0).

http://creativecommons.org/licenses/by/4.0/ (c) (i) Open Access

\begin{abstract}
Background: Malaria remains a dominant health issue among children in Ghana. We monitored the trend of long lasting insecticide net (LLIN) ownership and use and its impact on malaria and anaemia among children under five over the past decade in an area of intense, prolonged and seasonal malaria transmission. Methods: A total of 1717, 2155 and 1915 children were surveyed in June and 1717, 2155 and 1697 in November in 30 communities of the Hohoe Municipality in 2006, 2010 and 2015 respectively. The primary outcomes monitored were the trend of LLIN ownership, use and prevalence of malaria and anaemia through cross-sectional surveys. Findings: Results showed a significantly positive trend $(\mathrm{p}<0.001)$ in ownership of LLIN at $20.8 \%, 64.8 \%$ and $83.2 \%$ for 2006,2010 and 2016 respectively. The sharp increase in ownership between 2006 and 2010 accounted for a highly significant departure from trend $(\mathrm{p}<0.001)$. Similarly, the prevalence of LLIN use was $15.1 \%, 42.2 \%$ and $68.3 \%$ for 2006,2010 and 2016 respectively with a significant positive trend $(\mathrm{p}<0.001)$. The prevalence of malaria parasitaemia in June showed no significant drop over the three years studied. Anaemia prevalence was $7.9 \%, 5.3 \%$ and $11.1 \%$ for 2006, 2010 and 2015 respectively-Anaemia significantly increased $(\mathrm{p}<0.001)$ between 2010 and 2015 accounting for a significant departure from the initially decreasing trend $(\mathrm{p}<0.001)$. Malaria parasitaemia over the November surveys was $40.4 \%, 33.2 \%$ and $26.6 \%$ for
\end{abstract}


2006, 2010 and 2016 respectively, depicting a significant decline over the years of the study $(\mathrm{p}<0.001)$. A significant decrease $(\mathrm{p}=0.006)$ in anaemia was observed at $12.0 \%, 4.3 \%$ and $8.9 \%$ for 2006,2010 and 2015 respectively. A significant departure from the decreasing trend ( $p<0.001)$ was noted with increasing anaemia between 2010 and 2016. Interpretation: Ownership of LLIN and its use together with other indicators of malaria prevalence generally improved five years after the implementation of a malaria control programme. Ten years after programme implementation, consistent improvement was only in LLIN ownership and use. Also malaria prevalence indicators improved in the post as compared to the pre-rainy season in the study communities.

\section{Keywords}

Malaria, Anaemia, Long Lasting Insecticide Treated BedNets, Children under Five Years, Hohoe Municipality, Ghana

\section{Background}

Malaria is a focal problem of sub-Saharan Africa and for that matter Ghana. The condition is endemic in Ghana with Plasmodium falciparum ( $p f$ ) as the predominant species causing the disease [1] [2]. Malaria is defined as a fever with any parasitaemia; and anaemia that requires treatment as haemoglobin $(\mathrm{Hb})$ concentration of less than 8.0 gram/deciliter (g/dl) [3]. Globally, malaria and anaemia are major causes of morbidity and mortality among children under five years of age. A complication of malaria, anaemia is responsible for about $95 \%$ of malaria deaths worldwide with a mortality rate of $1 \%-3 \%$ [4]. As of 2007 , the population attributable risk percentage of $p$-induced anaemia in Ghana was 16.5\% [5]. Between 2000 and 2015, malaria incidence rates fell by $37 \%$ globally, and $42 \%$ in Africa. During this same period, malaria mortality rates fell by $60 \%$ globally and 66\% in the African Region [2].

Though indicators point to a drop in its occurrence, malaria remains a dominant health issue in Ghana. Some 2200 deaths out of about 3.5 million cases of malaria reported in Ghana in 2015 were significantly lower than figures from 2013 [2]. Malaria still tops most Out Patient Department (OPD) cases and kills 3 children every day in Ghana [6]. In the Hohoe Municipality in 2014, malaria was a leading cause of OPD attendance and overall deaths at $28 \%$ and $19.4 \%$ respectively. Out of the 40,092 cases of malaria seen at the Hohoe Municipal Hospital OPD, $3452(8.6 \%)$ were admitted. Children under 5 years of age constituted $42.1 \%$ (1452) of the cases admitted [7].

The Millennium Development Goals (MDGs) and the Abuja Declaration set targets of achieving $60 \%$ coverage of malaria interventions in pregnant women and children below 5 years of age by 2010 [8] and reducing malaria deaths and illness by $75 \%$ by 2015 [9]. Malaria control programmes premised on the above targets have facilitated reductions in deaths and illness attributable to malaria. 
Methods employed by malaria control programmes globally include the use of long lasting insecticide nets (LLINs), and early detection of malaria and appropriate and prompt management with artemisinin-based combination therapy (ACT) [10]. Others are indoor residual spraying (IRS) and the use of effective chemoprophylaxis or intermittent preventive treatment (IPT) [11]. ITN ownership and use among pregnant women and children under five years have improved over the past decade [10]. Tropical Africa has generally been identified as having a high coverage of combined malaria control interventions [12] [13]. Findings from malaria control programs using LLINs, ACT or IRS have shown a drastic decline in malaria deaths, malaria positive cases and malaria prevalence over the past decade [14] [15] [16]. Furthermore, the scale-up of LLINs and ACT use in case management has reduced the burden of malaria anaemia in children under five years of age [14] [17]. Long lasting Insecticide Nets have ultimately contributed to the reduction in malaria infections; malaria morbidity and mortality in children under five years of age [18] [19] [20] [21]. Owning a LLIN does not protect an individual from malaria but rather its effective use and ability of the LLIN to kill or prevent mosquitoes from biting individuals [19]. Also mosquito survival and numbers of sporozoite-positive mosquitoes reduced significantly in whole communities provided with LLINs [12].

Important roll back malaria (RBM) indicators that help in monitoring changes in malaria incidence and prevalence are the proportion of households that own one or more LLINs and the proportion of under-five children who sleep inside a LLIN [10]. LLIN ownership and utilization assess the effectiveness of distribution channels and the desired epidemiological impact respectively of the RBM programme [10]. Other indicators are the prevalence of fever, anaemia, $P$. falciparum parasitaemia and gametocytemia [10].

In line with attaining MDG targets of reducing malaria illness and deaths, the Ghana NMCP introduced LLINs, IPTs and ACTs into the Hohoe Municipality. Ahead of implementing the intervention, baseline surveys were carried out in June and November 2006 [22]. Follow up surveys were carried out in 2010 and 2015 to assess the influence of the intervention of LLINs, IPTs and ACTs use, as well as changes in malaria incidence and prevalence in the Municipality. The current manuscript reports on trends in LLIN use and malaria prevalence in children aged 6 to 59 months over the course of the surveys between 2006 and 2015 .

\section{Methods}

\subsection{Study Design}

The design of the three surveys was cross-sectional in nature. The surveys were carried out at the beginning of the rainy season (pre-rainy season) in June and the end (post-rainy season) in November) of the high transmission period for malaria in 2006, 2010 and 2015 respectively.

\subsection{Study Area}

The study was undertaken in the Hohoe Municipality of Ghana. The municipal- 
ity is one of the twenty-five administrative districts of the Volta Region with a population of 167,000 people. It has two main seasons-the wet and the dry. The major wet season is from April to July and the minor one from September to November each year. The rest of the year is relatively dry. The climate is tropical with temperatures varying between $22^{\circ} \mathrm{C}$ and $37^{\circ} \mathrm{C}$. The average annual rainfall in the municipality is $1592 \mathrm{~mm}$ with approximately $1296 \mathrm{~mm}$ of rain falling between April and October [23]. Malaria is hyperendemic in the study area but with seasonal peaks. The entomological inoculation rate (EIR) of malaria for the study area is approximately 65 (95\% CI: 0 - 143) infectious bites per person per year [3]. Malaria transmission occurs throughout the year with seasonal peaks, coinciding with the period of the rains (high malaria transmission begins from June and ends in November).

\subsection{Study Population}

The study population was all children in the municipality aged 6 to 59 months. To be eligible for the study, the child should be aged 6 - 59 months and the parents/guardians consented to participate.

\subsection{Sampling and Sample Size Calculation}

For the initial survey in 2006, thirty communities were selected from a sample frame of all villages and communities in the municipality. The number of children living in each community was determined from the 2000 census. Thirty communities with the required number of children for the study (2125) were randomly selected by probability proportional to the number of children living in each community. This sampling approach was used to ensure a fair representation of communities in the municipality in the study. The sample size was estimated on the basis of the following: 95\% confidence level $(Z)$ and power of $80 \%$, the prevalence $(\mathrm{P})$ of malaria in children aged less than 5 years in June 2006 (end of dry season) was 8.6\%. The least acceptable prevalence of malaria was 5.0\%. Using OpenEpi software version 3 [24], the sample size calculated for each of the cross sectional studies was 1648 children aged less than 5 years [25].

\subsection{Data Collection}

Data collection for each study was in three phases:

Phase 1: Parents/guardians of the sampled children were interviewed using a close-ended questionnaire to gather information among others on LLIN ownership and use.

Phase 2: Temperature and weight measurements were taken of the sampled children. Temperature was measured using electronic thermometers (MODE: ZC, SURGILAC Digital Thermometer, UK). Weight was measured using SECA weighing scales (Hamburg, Germany).

Phase 3: Finger-prick blood samples were collected from the sampled children to assess malaria parasitaemia (mps) and $\mathrm{Hb}$ levels. Two technicians ex- 
amined thick blood films for mps. A sample was considered negative only after 200 high power fields had been read. Parasite counts were converted to parasites per micro-liter $(\mu \mathrm{l})$, assuming a white blood cell count of 8000 leukocytes per $\mu \mathrm{l}$ of blood. If there was a discrepancy in the findings of a slide between the two technicians (positive or negative or a $50 \%$ or more difference in parasite density) a third, more senior microscopist provided a conclusive result. A senior microscopist from the School of Public Health of the University of Health and Allied Sciences examined all the positive blood films and a $20 \%$ random sample of negative blood slides for quality control. Haemoglobin was measured using URIT-12 Hemoglobin Meter (URIT Medical Electronic, UK).

\subsection{Data Management, Measures and Statistical Analysis}

Data collected from the study subjects were recorded on specified forms and checked by field supervisors and a data manager for consistency and accuracy. The data were double entered into a database using the EPI Data software version 3.1. The accuracy of data input was checked and validated using customized validation programmes. The cleaned data were exported into the STATA statistical software version 12 for analysis.

The main variables of interest were malaria prevalence measured by any malaria parasitaemia (asexual parasite count $40 / \mu l$ and above), high density parasitaemia (asexual parasite count $\geq 7000 / \mu l$, gametocytemia (sexual parasites), fever (axillary temperature $\geq 37.5^{\circ} \mathrm{C}$ ) and anaemia $(\mathrm{Hb}<8.0 \mathrm{~g} / \mathrm{dl})$ [26]. Other variables included age groupings in months, temperature and weight measurements, LLIN ownership and usage.

Analysis of the outcomes was carried out on an intention-to-treat basis, which implies that children screened were included in the analysis. Pre-rainy and post-rainy season measures of malaria parasitaemia, gametocytaemia, fever and anaemia in 2010 and 2015 were compared with those of the same periods of 2006. For each outcome a regression of its proportion was run using the Stata command ptrend. It reports the slope, standard error and z-score of the regression line, a chi square test for trend and a chi square test for departure from trend together with their corresponding p-values. All analyses were done with STATA software version 12.0. A negative slope was referred to as a negative trend, which implies a reduction in prevalence compared to the previous years. A positive slope was referred to as a positive trend, which implies an increase in prevalence over the previous years.

\subsection{Ethical Considerations}

Ethical approval for the study was obtained from the Ethical Review Committee (ERC) of the Ghana Health Service/Ministry of Health (GHS/MOH). The identification number for the clearance was ETHICS APPROVAL-ID NO: GHS-ERC: 14/05/15. Before the commencement of the study, permission was sought from the Municipal Health Management Team (MHMT), the Municipal Administra- 
tion and the chiefs and elders of the selected communities. Parents/guardians of the participating children signed a written informed consent form before the start of the study.

\section{Results}

\subsection{Background Characteristics of the Study Population}

The sample population of the study in 2015 was one thousand nine hundred and fifteen (1915) and one thousand six hundred and ninety-seven (1697) children less than five years in the pre-rainy and post-rainy seasons respectively. The population for June and November 2006 was 1717 and 1435 respectively, and that for 2010, 2155 and 1778 children respectively. Overall, sex, mean age and mean weight distribution were similar in all groups (Table 1).

\subsection{Trend of LLIN Ownership}

Table 2 shows that ownership of LLIN was 357 (20.8\%), 1396 (64.8\%) and 1593 (83.2\%) respectively for 2006, 2010 and 2016. The test of trend between 2006 and 2015 showed a significant positive trend $(\mathrm{p}<0.001)$. On the other hand the highly significant result for the departure from trend $(\mathrm{p}<0.001)$ is due to the high difference in ownership between 2006 and 2010 compared to that between 2010 and 2016. The prevalence of LLIN use was $15.1 \%, 42.2 \%$ and $68.3 \%$ respecttively for 2006, 2010 and 2016. The test of trend between 2006 and 2015 showed a significant positive trend $(\mathrm{p}<0.001)$ with no departure from it.

Table 1. Characteristics of children in all surveys.

\begin{tabular}{cccc}
\hline Variable & \multicolumn{3}{c}{ Pre-rainy season } \\
\hline Age groups (in months) & $\begin{array}{c}2006(\mathrm{~N}=1717) \\
{[\mathrm{n}(\%)]}\end{array}$ & $\begin{array}{c}2010(\mathrm{~N}=2155) \\
{[\mathrm{n}(\%)]}\end{array}$ & $\begin{array}{c}2015(\mathrm{~N}=1915) \\
{[\mathrm{n}(\%)]}\end{array}$ \\
\hline $6-11$ & $321(18.7)$ & $389(18.0)$ & $258(13.5)$ \\
$13-23$ & $435(25.3)$ & $510(23.7)$ & $428(22.3)$ \\
$24-35$ & $399(23.2)$ & $454(21.1)$ & $480(25.1)$ \\
$36-47$ & $319(18.6)$ & $436(20.2)$ & $377(19.7)$ \\
$48-59$ & $243(14.2)$ & $366(17.0)$ & $372(19.4)$ \\
Mean weight (kg) [SD] & $12.8(2.7)$ & $11.3(3.3)$ & $11.8(3.2)$ \\
Mean age (in months) [SD] & $27.3(15.4)$ & $27.8(15.5)$ & $30.6(15.6)$
\end{tabular}

Table 2. Trend of LLIN ownership and use at the beginning of the rainy season for years 2006, 2010 and 2015.

\begin{tabular}{cccccc}
\hline Variable & $\begin{array}{c}2006(\mathrm{~N}=1717) \\
{[\mathrm{n}(\%)]}\end{array}$ & $\begin{array}{c}2010(\mathrm{~N}=2155) \\
{[\mathrm{n}(\%)]}\end{array}$ & $\begin{array}{c}2015(\mathrm{~N}=1915) \\
{[\mathrm{n}(\%)]}\end{array}$ & $\begin{array}{c}X_{1}^{2}, \\
\mathrm{P}(\text { Trend })\end{array}$ & $\begin{array}{c}X_{1}^{2}, \\
\text { P (Depart.) }\end{array}$ \\
\hline Own LLIN & $357(20.8)$ & $1396(64.8)$ & $1593(83.2)$ & $1422,<0.001_{\mathrm{a}}$ & $90.6,<0.001$ \\
Use LLIN & $260(15.1)$ & $910(42.2)$ & $1307(68.3)$ & $2.1,<0.001_{\mathrm{b}}$ & $0.155,0.693$ \\
\hline \multicolumn{7}{l}{ a: Slope $=0.309$, std. error $=0.008, \mathrm{z}=37.72$; b: Slope $=0.265$, std. error $=0.008, \mathrm{z}=32.30}$.
\end{tabular}


Table 3. Trend of the primary and key secondary outcomes at the beginning of the rainy season for the years 2006, 2010 and 2015.

\begin{tabular}{cccccc}
\hline & 2006 & 2010 & 2015 & & \\
Variable & $\begin{array}{c}(\mathrm{N}=1717) \\
{[\mathrm{n}(\%)]}\end{array}$ & $\begin{array}{c}\mathrm{N}=2155) \\
{[\mathrm{n}(\%)]}\end{array}$ & $\begin{array}{c}\mathrm{N}=1915) \\
{[\mathrm{n}(\%)]}\end{array}$ & $\begin{array}{c}X_{1}^{2}, \\
\text { (Trend) }\end{array}$ & $\begin{array}{c}X_{1}^{2}, \\
\text { (Depart.) }\end{array}$ \\
\hline Fever (temp. $\geq 37.5)$ & $42(2.4)$ & $25(1.2)$ & $50(2.6)$ & $0.2,0.637_{\mathrm{a}}$ & $12.8,<0.001$ \\
Any malaria parasitaemia & $156(9.1)$ & $156(7.2)$ & $148(7.7)$ & $2.1,0.145_{\mathrm{b}}$ & $2.5,0.113$ \\
High density malaria parasitaemia & $50(2.9)$ & $49(2.3)$ & $43(2.2)$ & $1.6,0.203_{\mathrm{c}}$ & $0.5,0.469$ \\
Gametocytaemia & $14(0.8)$ & $3(0.1)$ & $7(0.4)$ & $4.1,0.043_{\mathrm{d}}$ & $6.7,0.010$ \\
Anaemia $(\mathrm{Hb}<8.0 \mathrm{~g} / \mathrm{dl})$ & $135(7.9)$ & $114(5.3)$ & $212(11.1)$ & $14.1,<0.001_{\mathrm{e}}$ & $32.1,<0.001$ \\
\hline
\end{tabular}

a: Slope $=0.001$, std. error $=0.002, z=0.472$; b: Slope $=-0.002$, std. error $=0.001, z=2.021$; c: Slope $=$ -0.003 , std. error $=0.003, z=1.273$; d: Slope $=-0.002$, std. error $=0.001, z=2.021$; e: Slope $=0.017$, std. error $=0.005, \mathrm{z}=3.756$.

\subsection{Pre-Rainy Season Malaria Parasitaemia, Fever, Anaemia and Gametocytaemia}

In Table 3, the proportions of children with fever in 2006, 2010 and 2016 were $2.4 \%, 1.2 \%$ and $2.6 \%$ respectively. The chi square test for trend showed that there was no significant linear trend between 2006 and $2015(\mathrm{p}=0.637)$, but there was a significant drop between 2006 and 2010 and a rise between 2010 and $2016(\mathrm{p}<0.001)$.

The prevalence of "any parasitaemia" was 9.1\%, 7.2\% and 7.7\% respectively for 2006, 2010 and 2016. The test of trend between 2006 and 2015 showed that even though there was a negative trend, it was not significant $(\mathrm{p}=0.145)$.

The prevalence of "high density parasitaemia" was $2.9 \%, 2.3 \%$ and $2.2 \%$ respectively for 2006, 2010 and 2015. The test of trend between 2006 and 2015 showed that even though there was a negative trend, it was not significant $(\mathrm{p}=$ $0.203)$.

The prevalence of gametocytemia was $0.8 \%, 0.1 \%$ and $0.4 \%$ respectively for 2006, 2010 and 2015. The test of trend between 2006 and 2015 showed that there was a negative trend and it was significant $(\mathrm{p}=0.043)$. The drop in prevalence between 2006 and 2010 and the rise in prevalence between 2010 and 2015 was a significant departure from the trend $(\mathrm{p}=0.010)$.

The prevalence of anaemia was $7.9 \%, 5.3 \%$ and $11.1 \%$ respectively for 2006 , 2010 and 2015. The test of trend between 2006 and 2015 showed a significant rise in cases of anaemia $(p<0.001)$. Even though there was a significant fall between 2006 and 2010, the rise between 2010 and 2015 was a significant departure from the trend $(\mathrm{p}<0.001)$.

\subsection{Post Rainy Season Prevalence of Malaria, Fever, Anaemia and Gametocytaemia}

In Table 4, the prevalence of "fever" (temperature $\geq 37.5^{\circ} \mathrm{C}$ ) was $4.9 \%, 4.3 \%$ and $2.6 \%$ respectively for 2006, 2010 and 2015. The test of trend between 2006 and 
Table 4. Analysis of trend of the primary and key secondary outcomes at the three studies during the post rainy season.

\begin{tabular}{|c|c|c|c|c|c|}
\hline Variable & $\begin{array}{c}2006 \\
(\mathrm{~N}=1717) \\
{[\mathrm{n}(\%)]}\end{array}$ & $\begin{array}{c}2010 \\
(\mathrm{~N}=2155) \\
{[\mathrm{n}(\%)]}\end{array}$ & $\begin{array}{c}2015 \\
(\mathrm{~N}=1915) \\
{[\mathrm{n}(\%)]}\end{array}$ & $\begin{array}{c}X_{1}^{2}, \\
\text { P (Trend) }\end{array}$ & $\begin{array}{c}X_{1}^{2}, \\
\text { P (Depart.) }\end{array}$ \\
\hline Fever (temp. $\geq 37.5$ ) & $71(4.9)$ & $77(4.3)$ & $44(2.6)$ & $11.8,0.001$ & $0.9,0.331$ \\
\hline Any malaria parasitaemia & $580(40.4)$ & $590(33.2)$ & $451(26.6)$ & $67.3,<0.001$ & $0.05,0.822$ \\
\hline High density malaria parasitaemia & $151(10.5)$ & $56(3.1)$ & $71(4.2)$ & $54.0,<0.001$ & $37.4,<0.001$ \\
\hline Gametocytaemia & $12(0.8)$ & $3(0.2)$ & $5(0.3)$ & $5.1,0.023$ & $4.4,0.036$ \\
\hline Anaemia $(\mathrm{Hb}<8.0 \mathrm{~g} / \mathrm{dl})$ & $172(12.0)$ & $76(4.3)$ & $151(8.9)$ & $7.7,<0.006$ & $57.6,<0.001$ \\
\hline
\end{tabular}

a: Slope $=-0.012$, std. error $=0.003, z=3.441$; : Slope $=-0.069$, std. error $=0.008, z=8.207$; : Slope $=$ -0.030 , std. error $=0.001, z=2.268$; d: Slope $=-0.003$, std. error $=0.001, z=2.257$; e: Slope $=-0.014$, std. error $=0.005, \mathrm{z}=2.772$.

2015 showed a significant reduction of cases of fever over the years studied ( $\mathrm{p}=$ $0.001)$.

The prevalence of "any parasitaemia" was $40.4 \%, 33.2 \%$ and $26.6 \%$ respectively for 2006, 2010 and 2016. The test of trend between 2006 and 2015 showed a significant reduction of "any parasitaemia" over the years of the study ( $\mathrm{p}<$ $0.001)$

The prevalence of "high density parasitaemia" was $10.5 \%, 3.1 \%$ and $4.2 \%$ respectively for 2006, 2010 and 2015. The test of trend between 2006 and 2015 showed a significant decrease in "high density parasitaemia" over the years studied $(\mathrm{p}<0.001)$. However, there was a fall between 2006 and 2010 and then a rise between 2010 and 2016 but not up to the level of 2006. The fall in prevalence between 2006 and 2010 and the rise between 2010 and 2015 formed a significant departure from the linear trend $(\mathrm{p}<0.001)$ (Table 4).

The prevalence of "gametocemia" was $0.8 \%, 0.2 \%$ and $0.3 \%$ respectively for 2006, 2010 and 2016. The test of trend between 2006 and 2015 showed a significant reduction over the study period $(\mathrm{p}=0.023)$. The fall in prevalence between 2006 and 2010 and the rise between 2010 and 2015 formed a significant departure from the linear trend $(\mathrm{p}=0.036)$ (Table 4).

The prevalence of anaemia was $12.0 \%, 4.3 \%$ and $8.9 \%$ respectively for 2006 , 2010 and 2015. The test of trend between 2006 and 2015 showed a significant decrease in cases of anaemia $(p=0.006)$. The fall in prevalence between 2006 and 2010 and the rise between 2010 and 2016 formed a significant departure from the linear trend $(\mathrm{p}<0.001)$ (Table 4).

\section{Discussions}

The study determined changes in indicators related to malaria prevalence among children below five years of age in the Hohoe Municipality of Ghana after interventions were introduced in 2006. This study has the unique quality of two five-year follow-ups post intervention. This has provided a longer-term view of 
the intervention effect in its immediate and long-term aftermath. There was a general increase in LLIN ownership and use. LLIN use consistently lagged behind LLIN ownership. Malaria parasitaemia, fever and anaemia levels fell within the first five years of the malaria control interventions, but were not sustained five years on.

This study shows an increase in LLIN ownership and use in the Hohoe municipality between 2006 and 2015 in the pre-rainy season. The findings are similar to surveys carried out in 2003, 2008 and 2014 that showed a consistent increase in ownership and use of LLINs in Ghana as a whole and in the Volta Region in particular (Ghana Demographic and Health Survey [GDHS], 2008 \& 2014). Just as in the current study population, LLIN use has been consistently lower than its ownership across populations in some earlier studies [27] [28] [29] [30] [31]. Scarcity of nets, hot and dry weather and "being too hot in the net" were some reasons for low LLIN use [28] [30]. A community-based participatory intervention in Ghana improved LLIN use in the study populations [32].

Significant reductions in $p f$ and anaemia were observed in children below 5 years after introduction of LLIN in Zanzibar $(\mathrm{p}<0.001)$ [13] and Western Kenya $(\mathrm{p}<0.0001)$ [33] respectively. Also malaria prevalence in children under five years of age decreased in Rwanda after the implementation of a programme that provided ACT and LLINs [14]. In the current study, fever, any parasitaemia, high-density parasitaemia, gametocytaemia and anaemia were the indicators used in assessing malaria prevalence. Significant improvements in malaria prevalence indicators were observed in the post-rainy than the pre-rainy season in the current study population between 2006 and 2010. These observed differences may lead to the suggestion that national malaria control programmes should further investigate the implementation of different interventions to suit each of the seasons. The improvements of malaria prevalence indicators between 2006 and 2010 were however not sustained between 2010 and 2015. Reports have shown that implementation of control activities decreases malaria from the baseline, but removing such control activities results in a return to baseline. Such a pattern has been observed in many locations where malaria control interventions have been successfully implemented and then halted. A review identified 75 different historical situations in which malaria resurged after it had been controlled [34]. Many of these resurgence events occurred at least in part because the reduction of malaria to very low levels led to an impression that transmission was no longer a threat, whereas the potential for transmission still existed. Sri Lanka and Zanzibar both experienced this kind of resurgence [10]. Possible reasons for the non-sustainability could also be due to delayed re-treatment of nets as identified in a study in Kenya [35]. Further investigations will be required into this situation.

The increasing LLIN ownership and use observed in this study did correspond to a continuous reduction in malaria prevalence during the high transmission but not the low transmission season. Studies in Kenya also made similar obser- 
vations [27].

The effectiveness of LLIN reduces over time. However, the net does not need to be sprayed periodically with insecticide over time to maintain its effectiveness. After a period of time, the net needs to be replaced. This fact could be the reason why despite an increase in LLIN ownership and usage in the current study, there was still an increase in gametocytaemia and anaemia. However, information on maintenance of LLIN was not collected from the net owners during the current study.

\section{Limitations of the Study}

This was a cross-sectional survey at one point of the end of the high transmission season and not a cohort study that can determine malaria incidence throughout the wet and dry seasons. Information on LLIN ownership and usage was obtained from parents of the children without observation to confirm the availability and use. Since this was not a cohort study, our interest was not to study a particular sample of children over the period of the study. However, there might be some overlap between the selected samples over the period of the study as measures were not put in place to ensure that different sets of children were evaluated in the three different periods of the study.

\section{Conclusion and Recommendations}

Long Lasting Insecticide Treated Net ownership and use together with other indicators of malaria prevalence generally improved five years after the implementation of a malaria control programme in the Hohoe Municipality. Ten years after program implementation consistent improvement was only in LLIN ownership and use. Also malaria prevalence indicators improved better in the post as compared to the pre-rainy season.

Considering the fact that LLIN ownership and use showed consistent improvement, there is the need to further investigate factors that contributed to other malaria prevalence indicators. In the meantime other measures such as seasonal malaria chemoprevention (SMC) and indoor insecticide paints among others should be employed by the Municipal Health Directorate in consultation with other stakeholders to improve malaria control indicators.

\section{Acknowledgements}

We are grateful to Dr. Felix Doe, the Hohoe Municipal Director of Health Services and Municipal Health Management Team for their assistance during the survey. We are also grateful to Mr. King Kpo, who monitored the quality of $\mathrm{Hb}$ measurement, prepared slides and read them. We are thankful to all the parents/guardians for consenting to them and their children to be part of the study.

\section{Conflict of Interest}

All authors report no conflict of interest in this study. 


\section{Authors' Contributions}

MK worked on the 2006 and 2015 projects and 2010 post-rainy season survey, supported EA on the 2010 pre-rainy season study who worked on this project for his MPH. MK, EA conceived the study. MK, YE, MA, WT, ET and JG were responsible for the initial draft of the manuscript. All authors reviewed and approved the final version of the manuscript.

\section{References}

[1] Koram, K.A., Abuaku, B., Duah, N. and Quashie, N. (2005) Comparative Efficacy of Antimalarial Drugs including ACTs in the Treatment of Uncomplicated Malaria among Children under 5 Years in Ghana. Acta Tropica, 95, 194-203. https://doi.org/10.1016/j.actatropica.2005.06.018

[2] World Health Organization (WHO) (2014) World Malaria Report 2014. http://www.who.int/malaria/publications/world_malaria_report_2014/en/

[3] Kweku, M., Liu, D., Adjuik, M., Binka, F., Seidu, M., Greenwood, B. and Chandramohan, D. (2008) Seasonal Intermittent, Preventive Treatment for the Prevention of Anaemia and Malaria in Ghanaian Children: A Randomized, Placebo Controlled Trial. PLoS ONE, 3, e4000. https://doi.org/10.1371/journal.pone.0004000

[4] WHO (2007) 2007 World Malaria Report. Geneva: World Health Organization.

[5] Ghana Health Service/Ministry of Health (GHS/MOH) (2007) 2007 Ghana Health Service/Ministry of Health Annual Report, Accra.

[6] Ghana Health Service (GHS) (2015) 2015 National Malaria Control Programme/Ghana Health Service Annual Report. Accra: Ghana Health Service.

[7] GHS (2014) 2014 Hohoe Municipal Health Directorate Annual Report. Hohoe: Ghana Health Service.

[8] Ghana Statistical Service (GSS)/Ghana Health Service (GHS) (2009) ICF International. Ghana Demographic and Health Survey 2008. Accra, Ghana: Ghana Statistical Service, Ghana Health Service, and ICF Macro.

[9] GHS (2009) 2009 National Malaria Control Programme/Ghana Health Service Annual Report. Accra: Ghana Health Service.

[10] WHO (2014) From Malaria Control to Malaria Elimination: A Manual for Elimination Scenario Planning.

[11] Ministry of Health, Ghana (2009) Ministry of Health Strategic Plan for Malaria Control in Ghana 2008-2015. Ministry of Health, Ghana, Accra.

[12] Curtis, C., Maxwell, C., Magesa, S., Rwegoshora, R. and Wilkes, T. (2006) Insecticide-Treated Bed-Nets for Malaria Mosquito Control. Journal of the American Mosquito Control Association, 22, 501-506. https://doi.org/10.2987/8756-971X(2006)22[501:IBFMMC]2.0.CO;2

[13] Bhattarai, A., Ali, A.S., Kachur, S.P., Martensson, A., Abbas, A.K., Khatib, R., Al-Mafazy, A.W., Ramsan, M., Rotllant, G., Gerstenmaier, J.F., Molteni, F., Abdulla, S., Montgomery, S., Kaneko, A. and Bjorkman, A. (2007) Impact of Artemisinin-Based Combination Therapy and Insecticide-Treated Nets on Malaria Burden in Zanzibar. PLoS Medicine, 4, Article ID: e309. https://doi.org/10.1371/journal.pmed.0040309

[14] Sievers, A.C., Lewey, J., Musafiri, P., Franke, M.F., Bucyibaruta, B.J., Stulac, S.N., Rich, M.L., Karema, C. and Daily, J.P. (2008) Reduced Paediatric Hospitalizations for Malaria and Febrile Illness Patterns following Implementation of Communi- 
ty-Based Malaria Control Programme in Rural Rwanda. Malaria Journal, 7, 1. https://doi.org/10.1186/1475-2875-7-167

[15] Delacollete, C., D’Souza, C., Chrstophel, E., Thimasaran, K., Abdur, R., Bell, D., Dai, T.C., Gopinath, D., Lu, S., Mendoza, R., Ortega, L., Rastrogi, R., Tantinimitkul, C. and Ehrenberg, J. (2009) Malaria Trends and Challenges in the Greater Mekoy Subregion. Southeast African Journal Tropical Medicine Public Health, 40, 17.

[16] Otten, M., Aregawi, M., Were, W., Karema, C., Medin, A., Bekele, W., et al. (2009) Initial Evidence of Reduction of Malaria Cases and Deaths in Rwanda and Ethiopia Due to Rapid Scale-Up of Malaria Prevention and Treatment. Malaria Journal, 8, 14. https://doi.org/10.1186/1475-2875-8-14

[17] Pardo, G., Descalzo, M.A., Molina, L., Custodio, E., Lwanga, M., Mangue, C., et al. (2006) Impact of Different Strategies to Control Plasmodium Infection and Anaemia on the Island of Bioko (Equatorial Guinea). Malaria Journal, 5, 10. https://doi.org/10.1186/1475-2875-5-10

[18] Baume, C.A. and Marin, M.C. (2008) Gains in Awareness, Ownership and Use of Insecticide-Treated Nets in Nigeria, Senegal, Uganda and Zambia. Malaria Journal, 7, 153. https://doi.org/10.1186/1475-2875-7-153

[19] Binka, F. and Akweongo, P. (2006) Prevention of Malaria Using ITNs: Potential for Achieving the Millennium Development Goals. Current Molecular Medicine, 6, 261-267. https://doi.org/10.2174/156652406776055203

[20] Oresanya, O.B., Hoshen, M. and Sofola, O.T. (2008) Utilization of Insecticide-Treated Nets by Under-Five Children in Nigeria: Assessing Progress towards the Abuja Targets. Malaria Journal, 7, 145. https://doi.org/10.1186/1475-2875-7-145

[21] Kassile, T. (2012) Prevention and Management of Malaria in Under-Five Children in Tanzania: A Review. Tanzania Journal of Health Research, 14, 226. https://doi.org/10.4314/thrb.v14i3.10

[22] Kweku, M., Appiah, E.K., Takramah, W., Enuameh, Y., Norman, I. and Binka, F. (2015) Effect of a Malaria Control Program on the Prevalence of Malaria, Fever and Anaemia in Children under Five Years in the Hohoe Municipality of Ghana: A Comparative Analysis of Cross-Sectional Surveys. Advances in Infectious Diseases, 5, 180. https://doi.org/10.4236/aid.2015.54023

[23] Ghana Meteorological Services (2008) Hohoe Meterological Department Annual Report. Ghana Meteorological Services, Hohoe.

[24] Dean, A., Sullivan, K. and Soe, M. (2014) OpenEpi: Open Source Epidemiologic Statistics for Public Health, Version 2.3.1.

[25] Fleiss, J.L., Levin, B. and Paik, M.C. (2013) Statistical Methods for Rates and Proportions. John Wiley \& Sons, Hoboken.

[26] Drakeley, C.J., Jawara, M., Targett, G.A.T., Walraven, G., Obisike, U., Coleman, R., Pinder, M. and Sutherland, C.J. (2004) Addition of Artesunate to Chloroquine for Treatment of Plasmodium Falciparum Malaria in Gambain Children Casues a Significant but Short-Lived Reduction in Infectiousness for Mosquitoes. Tropical Medicine \& International Health, 9, 53-61. https://doi.org/10.1046/j.1365-3156.2003.01169.x

[27] Atieli, H.E., Zhou, G., Afrane, Y., Lee, M.C., Mwanzo, I., Githeko, A.K., et al. (2011) Insecticide-Treated Net (ITN) Ownership, Usage, and Malaria Transmission in the Highlands of Western Kenya. Parasites \& Vectors, 4, 113.

https://doi.org/10.1186/1756-3305-4-113

[28] Ezeigbo, O., Ejike, E. and Nwachukwu, I. (2016) Insecticide-Treated Bed Net (ITN): 
Ownership and Usage in the Control of Malaria in Abia State, Nigeria. American Journal of Epidemiology and Infectious Disease, 4, 42-46.

[29] Pettifor, A., Taylor, E., Nku, D., Duvall, S., Tabala, M., Meshnick, S., et al. (2008) Bed Net Ownership, Use and Perceptions among Women Seeking Antenatal Care in Kinshasa, Democratic Republic of the Congo (DRC): Opportunities for Improved Maternal and Child Health. BMC Public Health, 8, 331. https://doi.org/10.1186/1471-2458-8-331

[30] Korenromp, E.L., Miller, J., Cibulskis, R.E., Kabir, C.M., Alnwick, D. and Dye, C. (2003) Monitoring Mosquito Net Coverage for Malaria Control in Africa: Possession versus Use by Children under 5 Years. Tropical Medicine \& International Health, 8, 693-703. https://doi.org/10.1046/j.1365-3156.2003.01084.x

[31] Deressa, W., Fentie, G., Girma, S. and Reithinger, R. (2011) Ownership and Use of Insecticide-Treated Nets in Oromia and Amhara Regional States of Ethiopia Two Years after a Nationwide Campaign. Tropical Medicine \& International Health, 16, 1552-1561. https://doi.org/10.1111/j.1365-3156.2011.02875.x

[32] Rickard, D.G., Dudovitz, R.N., Wong, M.D., Jen, H.C., Osborn, R.D., Fernandez, H.E., et al. (2011) Closing the Gap between Insecticide Treated Net Ownership and Use for the Prevention of Malaria. Progress in Community Health Partnerships. Research, Education, and Action, 5, 123-131. https://doi.org/10.1353/cpr.2011.0018

[33] Kuile, F.O., Terlouw, D.J., Kariuki, S.K., Phillips-Howard, P.A., Mirel, L.B., Hawley, W.A., et al. (2003) Impact of Permethrin-Treated Bed Nets on Malaria, Anemia, and Growth in Infants in an Area of Intense Perennial Malaria Transmission in Western Kenya. The American Journal of Tropical Medicine and Hygiene, 68, 68-77. https://doi.org/10.1186/1475-2875-11-122

[34] Cohen, J.M., Smith, D.L., Cotter, C., Ward, A., Yamey, G., Sabot, O.J., et al. (2012) Malaria Resurgence: A Systematic Review and Assessment of Its Causes. Malaria Journal, 11, 122.

[35] Phillips-Howard, P.A., Nahlen, B.L., Kolczak, M.S., Hightower, A.W., Kuile, F.O., Alaii, J.A., et al. (2003) Efficacy of Permethrin-Treated Bed Nets in the Prevention of Mortality in Young Children in an Area of High Perennial Malaria Transmission in Western Kenya. The American Journal of Tropical Medicine and Hygiene, 68, 23-29.

Submit or recommend next manuscript to SCIRP and we will provide best service for you:

Accepting pre-submission inquiries through Email, Facebook, LinkedIn, Twitter, etc. A wide selection of journals (inclusive of 9 subjects, more than 200 journals)

Providing 24-hour high-quality service

User-friendly online submission system

Fair and swift peer-review system

Efficient typesetting and proofreading procedure

Display of the result of downloads and visits, as well as the number of cited articles

Maximum dissemination of your research work

Submit your manuscript at: http://papersubmission.scirp.org/

Or contact aid@scirp.org 